\title{
Glucose Lowering Effect of Brown Pigmented Rice (oryza sativa 1) in Diet-Induced Hyperglycemic Sprague Dawley Rats
}

\author{
Heni Purwaningsih ${ }^{\mathrm{a},}{ }^{*}$, Wilma A. Hurtada ${ }^{\mathrm{b}}$, Aimee Sheree A. Barrion ${ }^{\mathrm{b}}$, Marites G. Yee ${ }^{\mathrm{b}}$, \\ Josefina T. Dizon ${ }^{c}$, Siti Nuryanti ${ }^{\mathrm{d}}$ \\ ${ }^{a}$ Yogyakarta Assessment Institute of Agriculture Technology, Yogyakarta, Indonesia \\ ${ }^{b}$ Institute of Human Nutrition and Food, University of the Philippines Los Baños, Laguna, Philippines \\ ${ }^{c}$ College of Public Affairs and Development, University of the Philippines Los Baños, Laguna, Philippines \\ ${ }^{d}$ Faculty of Teacher Training and Education, Tadulako University, Central Sulawesi, Indonesia \\ Corresponding author: *heny_yk@yahoo.com
}

\begin{abstract}
The study investigated the dietary fiber and glycemic index of the three varieties of brown pigmented rice, namely, Inpari 24, Mawar, and Segreng, and the hypoglycemic effect of the rice variety with the highest dietary fiber and low glycemic index in hyperglycemic Sprague Dawley rats. Study phases included: 1) chemical analysis such as dietary fiber and amylose content, and proximate analysis of brown pigmented rice, 2) intervention phase 1: determination of effective dose of brown pigmented rice; and 3) intervention phase 2: in vivo evaluation of hypoglycemic effects of brown pigmented rice. Segreng variety contained the highest dietary fiber and lowest glycemic index. At the end of the intervention period, the effective dose to lower the blood glucose level was $75 \%$ cooked brown pigmented rice and $25 \%$ commercial rodent feed combination with a reduction of $54.57 \%$. And its reduction was comparable to the blood glucose level of rats given glibenclamide treatment $(58.24 \%)$. A significant positive correlation for blood glucose with calorie, carbohydrate, and fat was also observed. Therefore, the consumption of cooked brown pigmented rice can lower blood glucose levels in hyperglycemic Sprague Dawley rats. Furthermore, the glucose-lowering could be due to the dietary fiber and amylose content of brown pigmented rice. Further study is recommended using human subjects, and it may also be replicated using other grains like corn, adlai, sorghum, and root crops.
\end{abstract}

Keywords - Brown pigmented rice; low glycemic index; high dietary fiber; blood glucose level.

\section{INTRODUCTION}

Lifestyle changes and community consumption patterns of food impact the increasing degenerative diseases such as diabetes mellitus (DM). The World Health Organization (WHO) estimates that the prevalence of DM in Indonesia continues to increase. The Indonesia WHO predicts an increase in patients from 8.4 million in 2000 to about 21.3 million in 2030. Based on the population growth pattern expected in 2030, there will be 194 million people aged 20 years and an estimated prevalence of diabetes in urban and rural areas at $14.7 \%$ and $7.2 \%$, respectively. Seeing the rising prevalence of DM in different regions, it has been predicted that DM disease complications will develop into one of the major causes of morbidity and mortality in Indonesia in the future.
Diabetes mellitus (DM) is a syndrome characterized by chronic hyperglycemic conditions, carbohydrate, fat, and protein metabolism disorders associated with an absolute or relative deficiency of secretion and or insulin action [1]. Food that raises blood glucose levels rapidly has a high glycemic index (GI), while low glycemic index food will raise blood glucose levels slowly. A previous study suggested that low glycemic index food may improve metabolic control in patients with Type 2 diabetes mellitus in adults [2]. Factors that affect GI in foods include fiber content, the ratio of amylose and amylopectin, digestibility of starch, fat, and protein, and processing methods [3] that can contribute and influence each other to produce a specific glycemic response. A high dietary fiber contributes to a low GI value where fiber can be a barrier to physical digestion. Fiber can slow the rate of food in the digestive tract and inhibits the enzyme activity so that the process of digestion in particular starch [4] becomes slow, and the response of blood glucose would be 
lower. Thus, GI tends to be lower [5]. In addition, various studies also showed that food that has a higher proportion of amylose than amylopectin has lower GI values and vice versa [6]-[8]. In the management of diabetes, some efforts that can be made are medication, increased physical activity, and diet management. In diet management, low glycemic index [9], resistant starch [7], and food factors [10] showed initial improvements in blood glucose levels in mice and diabetics.

As glucose in the body comes from carbohydrates, the intake of staple high carbohydrate rice is an issue in preventing and treating diabetes. Hence, the specific effects of GI and fiber on postprandial glycemia from different types of rice are deemed important in providing a healthful diet for diabetes.

The consumption of natural foods like whole grains or brown rice is seen as a potential solution to preventing and managing food-related diseases in rice-producing and consuming countries like Indonesia. Brown rice was reported to contain high amounts of dietary fiber and may not cause blood sugar to increase sharply but keep it in check (Figure 1). However, limited information exists concerning the impact of brown rice meals in lowering the incidence of diabetes. Thus, the study's general objective was to evaluate the glucose-lowering effect of brown pigmented rice in hyperglycemic Sprague Dawley rats.

\section{MATERIALS AND METHOD}

The study consists of 3 phases: 1) Conduct of chemical analyses, 2) Intervention Phase 1: Determination of effective dose in Sprague Dawley rats, and 3) Intervention Phase 2: In vivo determination of the glucose-lowering activity of the effective dose. The general flow of the study is shown in Figure 1.

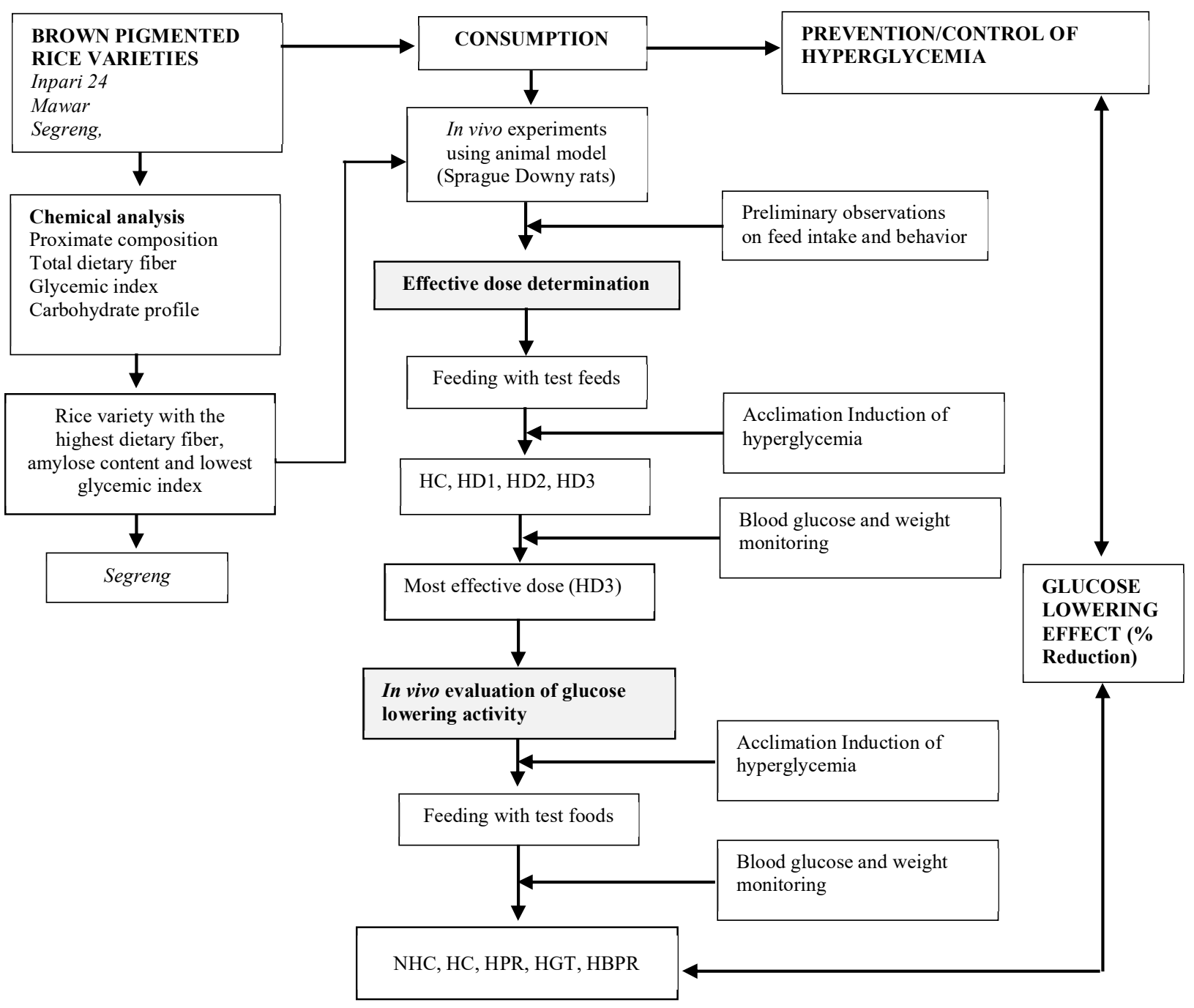

Fig. 1 Flow of the study

(Note: HC: commercial rodent feed; HD1:25\% cooked brown pigmented rice $+75 \%$ commercial rodent feed; HD2: $50 \%$ cooked brown pigmented rice $+50 \%$ rodent feed; HD3: 75\% cooked brown pigmented rice $+25 \%$ commercial rodent feed; NHC: non-hyperglycemic rats fed commercial feed; HC: negative control, hyperglyemic, rats fed commercial rodent feed; HPR: negative control, hyperglycemic rats fed $50 \%$ cooked well milled and $50 \%$ commercial rodent feed; HGT: positive control, hyperglycemic rats fed commercial rodent feed plus $10 \mathrm{mg} / \mathrm{kg} \mathrm{BW}$ of Glibenclamide drug; HBPR: hyperglycemic rats fed effective dose of $25 \%$ commercial rodent feed and $75 \%$ cooked brown pigmented rice. 


\section{A. Chemical Analyses}

At present, pigmented rice varieties have received attention from consumers due to their high nutritional value and bioactive compounds, which have potential benefits including antioxidant, anti-inflammatory, anticancer, and antidiabetic[11]. Some pigmented rice has grains of various colors such as yellow, green, brown, red, purple and black. Pigmented rice contains antioxidant nutrients, and has the potential to improve human health by managing various metabolisms [12].

Three pigmented rice varieties, namely, Inpari 24, Mawar, and Segreng, were procured from Yogyakarta Assessment Institute for Agriculture Technology. Then, it was dehulled in the Food and Nutrition Gadjah Mada University. The brown (dehulled) pigmented rice was packed in moisture-proof containers and was stored in a clean, cool, and dry place for later use in the study. The dehulled rice grains were analyzed for proximate composition (moisture, total ash, crude fat, protein), carbohydrate profile (amylose and amylopectin), dietary fiber using the procedures as described in the Association of Official Analytical Chemists [13]. At the same time, the glycemic index was determined in vivo. The rice variety with a relatively high amount of dietary fiber, amylose content, and the low glycemic index was the sample used in the in vivo evaluation of the glucose-lowering effect among hyperglycemic Sprague Dawley rats.

\section{B. Preparation and Acclimatization of Test Animals}

Eight (8) Sprague Dawley, 6-8 weeks old and weighing between 150-250g, were acclimatized for one week for adaptation in captivity and feed before the experiment. Rats were placed in Stainless steel cages. Feeds and drinks were given ad libitum. Environmental enclosures were maintained with a relative humidity of $60-70 \%$ at a temperature of about $25^{\circ} \mathrm{C}$, with alternating exposures to light and dark conditions at 12 hours intervals. Each group of 2 rats was placed in separate cages to avoid interaction with each other.

\section{Preliminary observation}

The usual food intake was observed using the same 8 rats during acclimatization. Sprague Dawley rats were grouped into four (4), and each group was assigned a specified test food; the rats were fed with: 1) cooked pigmented rice; 2) cooked white rice; 3) high fat (HF) rodent feed, and 4) $50 \%$ white rice and $50 \% \mathrm{HF}$. The feeding was done for seven days. Furthermore, blood glucose levels were measured before and after the intake of the test foods. Then, all animals were killed at the end of the experiment.

\section{Induction of Hyperglycemia}

Hyperglycemia in Sprague Dawley rats was induced with Streptozotocin (STZ) at $60 \mathrm{mg} / \mathrm{kg}$ body weight, dissolved in $0.1 \mathrm{M}$ citrate, $\mathrm{pH}$ 5.5. Before induction, rats were fasted for 12 hours. Then blood glucose was measured. After three days from induction, fasting blood glucose levels were measured, and only Sprague Dawley rats with blood glucose levels of $>$ $200 \mathrm{mg} / \mathrm{dL}$ were further used in the experiments.

\section{E. Determination of effective dose (Figure 1)}

Before induction of hyperglycemia, acclimatization and observation of the usual food intake were done. A total of 24 hyperglycemic Sprague Dawley rats were divided into four groups: One (1) hyperglycemic control group and three (3) treatment groups with six rats for each group. The hyperglycemic control (HC) was given commercial rodent feed (CRF) only. While for the treated groups: Treatment 1 (HF1) was given $25 \%$ cooked pigmented rice (CPR) and $75 \%$ CRF; Treatment 2 (HD2) with 50\% CPR and 50\% CRF; and Treatment 3 (HD3) with 75\% CPR and 25\% CRF.

Fasting blood glucose level was measured before induction and after three days from induction. The hyperglycemic rats' fasting blood glucose and feed intake were measured at baseline (Week 0) and every week after that during the entire one-month intervention period. All rats were killed at the end of the intervention period.

\section{F. In vivo Determination of the Glucose-lowering Activity of the Effective Dose (Figure 1)}

The procedure for acclimatization, preliminary observation, and induction of hyperglycemia used in effective dose determination was implemented. Another set of Sprague Dawley rats was used. A total of 30 Sprague Dawley rats: 6 non-hyperglycemic and 24 hyperglycemic, were used to determine the glucose-lowering effect of cooked brown pigmented rice. The procedure for induction of hyperglycemia that was used in effective dose determination was implemented. Five (5) groups were created, with six rats in each group. This includes four (4) control groups and one (1) treatment group. The four control groups were composed of: non-hyperglycemic rats which received commercial rodent feed only (NHC), hyperglycemic rats (negative control) fed with commercial rodent feed only (HC), hyperglycemic rats (negative control) fed with $50 \%$ cooked well-milled and $50 \%$ commercial rodent feed (HPR), and hyperglycemic rats (positive control) were given commercial rodent feed plus 10 $\mathrm{mg} / \mathrm{kg} \mathrm{BW}$ of Glibenclamide drug (HGT). The treated group was given the effective dose of $25 \%$ commercial rodent feed and $75 \%$ cooked brown pigmented (HBPR).

\section{G. Blood Glucose Measurement}

Fasting blood glucose level was measured at baseline (Week 0) and every week, after that, for the entire one-month duration of the intervention using blood Glucose Measurement (GOD-PAP method. Serum samples were centrifuged to separate the blood plasma from other substances in the blood. Then the samples were pipetted into the cuvettes and were incubated for 20 minutes at room temperature $\left(37^{\circ} \mathrm{C}\right)$. The absorbance was read in the spectrophotometer at $546 \mathrm{~nm}$. And blood glucose level was obtained using the formula:

$\mathrm{C}(\mathrm{mg} / \mathrm{dL})=($ Asp/Astd $)(100)$

Where:

$$
\mathrm{C}=\text { Blood glucose levels }
$$

Asp = absorbance sample

Astd $=$ absorbance standard

\section{H. Body weight measurement}

Cumulative change in body weight was measured every week for one month using a digital weighing scale. Measurements were done in the morning at 8 o'clock and recorded to the nearest 0.01 gram. Moreover, the change in 
body weight of the rats was determined using the following equation:

$\%$ Change in body weight $(\mathrm{g})=\left[\left(\mathrm{W}_{0}-\mathrm{W}_{1,2,3,4)} / \mathrm{W}_{0}\right](100)\right.$ Where:

$$
\mathrm{W} 0=\text { weight }(\mathrm{g}) \text { at Week } 0 \text { (baseline) }
$$

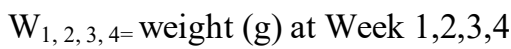

\section{Feed intake measurement}

Feed intake of the rats was measured every day for 30 days. The amount of feed intake was determined by subtracting the weight of the left-over feeds to the known weight of the initial feed given feed intake. Measurements were done in the morning at 8 o'clock and recorded to the nearest 0.01 gram.

\section{J. Statistical Analysis}

All data gathered were reported as mean \pm SD. The data were analyzed using the Analysis of Variance (ANOVA) using the Statistical Package for Social Science (SPSS) version 22.0. T-statistics was used to determine the level of significance using Microsoft Office Excel software. The probability value of $\leq 0.05$ was considered as a significant result. And bivariate correlation analysis was also done using SPSS.

\section{RESULTS AND DISCUSSION}

\section{A. Chemical Analyses}

Segreng was the variety selected for the intervention phase because it showed relatively high amounts of dietary fiber at $59.59 \%$, with moderate amylose content of $17.22 \%$ and also moderate glycemic index value of 55 (Table 1).

TABLE I

GLYCEMIC INDEX, DIETARY FIBER, AMYLOSE AND AMYLOPECTIN CONTENTS OF BROWN PIGMENTED RICE

\begin{tabular}{lccc}
\hline Variety & $\begin{array}{c}\text { Glycemic } \\
\text { Index (GI)* }\end{array}$ & $\begin{array}{c}\text { Dietary Fiber } \\
(\mathbf{\%})\end{array}$ & $\begin{array}{c}\text { Amylose } \\
(\mathbf{\%})\end{array}$ \\
\hline Mawar & $59.79^{\mathrm{a}}$ & $4.78^{\mathrm{a}}$ & $19.65^{\mathrm{a}}$ \\
Inpari 24 & $59.95^{\mathrm{a}}$ & $4.37^{\mathrm{a}}$ & $15.06^{\mathrm{b}}$ \\
Segreng & $55.00^{\mathrm{b}}$ & $5.59^{\mathrm{b}}$ & $17.22^{\mathrm{c}}$ \\
\hline
\end{tabular}

* Moderate (55-70) classification of GI value. Means in a column with same letter(s) are not significantly different . at $\alpha=0.05$ using t-test.

\section{B. Preparation and Acclimatization}

Sprague Dawley rats, 6-8 weeks old and weighing between 150-250g, which were acclimatized for one week (7 days) for adaptation in captivity and feed before the experiment, generally experienced weight gain between 9.5 and $10.5 \mathrm{~g}$. The mean food intake was around $12.52 \mathrm{~g} /$ day. All the rats were observed to be healthy. Environmental enclosures were maintained with a relative humidity of $60-70 \%$ at a temperature of about $25^{\circ} \mathrm{C}$ and alternating exposures to light and dark conditions at 12 hours intervals. This means that the room temperature and humidity conditions during acclimatization provided proper growth and development of the rats.

\section{Induction of Hyperglycemia}

The blood glucose levels of the rats before injection was between $55-59 \mathrm{mg} / \mathrm{dL}$ and after injection of STZ was 212-219 $\mathrm{mg} / \mathrm{dL}$ indicating hyperglycemic condition.

\section{Determination of Effective Dose}

HC (hyperglycemic control) has the highest feed intake compared with HD1, HD2, and HD3. At the end of the intervention period, the percent cumulative change in the feed intake of $\mathrm{HC}$ rats decreased by about $0.56 \%$, while feed intake increased in HD1, HD2, and HD3 rats. The highest feed intake was observed in HD3 rats and the lowest in HD1 rats. The treated groups consistently decreased from week 1 to 4 , with the highest percent cumulative increase observed in HD3 rats (Table II).

TABLE II

Weekly Mean Feed Intake, Percent Change in Feed Intake, and in FASTING BLOOD GLUCOSE OF FEED-INDUCED HYPERGLYCEMIC SPRAGUE DAWLEY RATS IN EFFECTIVE DOSE DETERMINATION

\begin{tabular}{|c|c|c|c|c|}
\hline $\begin{array}{c}\text { Treatment } \\
\text { Group }\end{array}$ & Week 1 & Week 2 & Week 3 & Week 4 \\
\hline & \multicolumn{4}{|c|}{ Weekly mean feed intake $(\mathrm{g})$} \\
\hline $\mathrm{HC}$ & $14.17 \pm 0.16$ & $13.95 \pm 0.16$ & $13.93+0.16$ & $13.98 \pm 0.17$ \\
\hline HD1 & $11.89+0.16$ & $12.12 \pm 0.17$ & $11.98 \pm 0.17$ & $12.00 \pm 0.17$ \\
\hline HD2 & $11.76 \pm 0.16$ & $12.04 \pm 0.17$ & $11.74 \pm 0.34$ & $12.00 \pm 0.17$ \\
\hline HD3 & $11.69 \pm 0.17$ & $11.57 \pm 0.17$ & $11.45 \pm 0.17$ & $12.00 \pm 0.17$ \\
\hline \multicolumn{5}{|c|}{ Weekly mean percent change in feed intake* } \\
\hline $\mathrm{HC}$ & $-2.23 \pm 2.59^{\mathrm{a}}$ & $0.32 \pm .90^{\mathrm{b}}$ & $-.40 \pm 2.64^{\mathrm{b}}$ & $0.56 \pm 3.84^{\mathrm{c}}$ \\
\hline HD1 & $12.44 \pm 7.59^{\mathrm{a}}$ & $7.59 \pm 10.54^{\mathrm{a}}$ & $-1.54 \pm 6.88^{\mathrm{b}}$ & $-2.82 \pm 7.49^{b}$ \\
\hline $\mathrm{HD} 2$ & $16.90 \pm 10.46^{\mathrm{a}}$ & $-1.98 \pm 3.97^{\mathrm{b}}$ & $1.88 \pm 9.31^{\mathrm{c}}$ & $-\overline{0.47 \pm 10.23^{\mathrm{d}}}$ \\
\hline HD3 & $16.25 \underline{\mathrm{c}} 9.58^{\mathrm{a}}$ & $\begin{array}{l}-0.39 \pm \\
12.73^{\mathrm{b}}\end{array}$ & $2.48+4.89^{c}$ & $-7.04 \pm 5.12^{\mathrm{d}}$ \\
\hline \multicolumn{5}{|c|}{ Weekly mean percent change in blood glucose level* } \\
\hline $\mathrm{HC}$ & $-.78 \pm 5.76^{\mathrm{a}}$ & $-.09 \pm 4.39^{\mathrm{a}}$ & $1.04 \pm 4.39^{\mathrm{b}}$ & $0.58+4.19^{\mathrm{b}}$ \\
\hline HD1 & $9.07 \pm 2.13^{\mathrm{a}}$ & $3.88+1.70^{\mathrm{b}}$ & $11.30+2.16^{\mathrm{c}}$ & $25.2 \pm 2.27^{\mathrm{d}}$ \\
\hline $\mathrm{HD} 2$ & $9.07 \pm 2.13^{\mathrm{a}}$ & $3.88 \pm 1.70^{\mathrm{b}}$ & $\begin{array}{l}11.36^{-} \\
2.16^{\mathrm{c}}\end{array}$ & $25.2 \pm 2.27^{\mathrm{d}}$ \\
\hline HD3 & $15.44 \pm 2.61^{\mathrm{a}}$ & $7.62 \pm 2.86^{\mathrm{b}}$ & $13.19+2.90^{\mathrm{a}}$ & $27.02+2.85^{\mathrm{c}}$ \\
\hline
\end{tabular}

"Negative (-) value means to increase; Positive (+) value means decrease. C-commercial rodent feed; BPR-brown pigmented rice; HC: hyperglycemic control, commercial rodent feed; HD1: $75 \%$ commercial feed and $25 \%$ commercial feed; HD2: $50 \%$ commercial feed and 50\% BPR: HD3: $25 \%$ commercial feed and $75 \%$ brown pigmented rice. Means within a group with the same letter(s) are not significantly different at $\alpha=0.05$ using ttest. Average normal blood glucose from acclimatization $=56.67 \mathrm{mg} / \mathrm{dL}$

Mean blood glucose levels in all groups did not differ statistically at baseline. However, at the end of the intervention period, the blood glucose level in HD1, HD2, and $\mathrm{HD} 3$ rats decreased except for $\mathrm{HC}$ rats and $\mathrm{HD} 3$ rats exhibited the highest reduction (Figure 2).

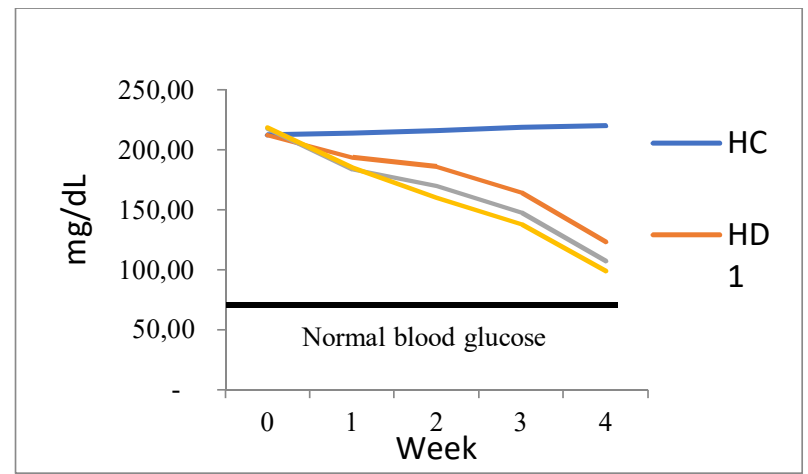

Fig. 2 Weekly mean blood glucose level in feed-induced hyperglycemic Sprague Dawley rats in the effective dose determination 
The reduction of blood glucose level among HD1, HD2 and HD3 rats differed significantly with one another as well as with the HC rats. Furthermore, none of the HD1, HD2 and HD3 rats exhibited blood glucose level at or below the normal blood glucose value of $56.67 \mathrm{mg} / \mathrm{dL}$ but HD3 rats was nearest approaching the normal value. Weekly percent mean changes in blood glucose level of the three treatment groups consistently decreased from week 1 to 4 with highest present cumulative decrease observed in HD3 rats (TABLE II). The HD3 rats fed with $75 \%$ BPR and $25 \%$ commercial rodent feed manifested the highest glucose lowering effect and thus, the effective dose used in the in vivo experiment.

\section{E. In vivo Glucose Lowering Effect of the $75 \%$ BPR and $25 \%$ commercial rodent feed}

Weight gain occurred in HGT, HPR, and HBPR rats from week 1 to week 4where HBPR group had the highest weight gain but was not significantly different from HGT and HPR groups. While lowest weight gain was observed in $\mathrm{HC}$ rats (Table III).

TABLE III

Weekly Mean Weight, Percent Change in Weight, Percent Change IN BLOOd GLuCose LEVEL IN FEED-INDUCED HyPERLIPIDEMIC SPRAGUE DAWLEY RATS FOR THE INVIVO GLUCOSE LOWERING DETERMINATION OF SEGRENG BROWN RICE

\begin{tabular}{|c|c|c|c|c|c|}
\hline $\begin{array}{l}\text { Treatment } \\
\text { group }\end{array}$ & Week 1 & Week 2 & Week 3 & Week 4 & \%Reduction \\
\hline \multicolumn{6}{|c|}{ Weekly mean weight $(\mathrm{g})$} \\
\hline NHC & $\begin{array}{r}185.00 \pm \\
0.29 \mathrm{a}\end{array}$ & $\begin{array}{r}190.00 \pm \\
0.81 \mathrm{a}\end{array}$ & $\begin{array}{r}196.00 \pm \\
0.47 \mathrm{~b}\end{array}$ & $189.00 \pm 1.14 b$ & - \\
\hline $\mathrm{HC}$ & $\begin{array}{r}239.00 \pm \\
0.98 \mathrm{a}\end{array}$ & $\begin{array}{r}250.83 \pm \\
0.75 b\end{array}$ & $\begin{array}{r}263.67 \pm \\
0.75 \mathrm{c}\end{array}$ & $275.83 \pm 1.03 \mathrm{~d}$ & - \\
\hline HGT & $\begin{array}{r}239.00 \pm \\
0.75 \mathrm{a}\end{array}$ & $\begin{array}{r}247.00 \pm \\
0.52 b\end{array}$ & $\begin{array}{r}252.67 \pm \\
0.82 \mathrm{c}\end{array}$ & $258.83 \pm 1.03 \mathrm{c}$ & - \\
\hline HPR & $\begin{array}{r}241.70 \pm \\
1.80 \mathrm{a}\end{array}$ & $\begin{array}{r}249.83 \pm \\
1.41 \mathrm{~b}\end{array}$ & $\begin{array}{r}259.33 \pm \\
1.21 \mathrm{c}\end{array}$ & $268.17 \pm 1.60 \mathrm{~d}$ & - \\
\hline HBPR & $\begin{array}{r}246.50 \pm \\
0.52 \mathrm{a}\end{array}$ & $\begin{array}{r}254.83 \pm \\
1.03 \mathrm{~b}\end{array}$ & $\begin{array}{r}263.00 \pm \\
0.75 \mathrm{c}\end{array}$ & $270.67 \pm 1.02 \mathrm{~d}$ & - \\
\hline \multicolumn{6}{|c|}{ Weekly mean percent change in weight * } \\
\hline NHC & $\begin{array}{r}-3.70 \pm \\
0.57 \mathrm{a}\end{array}$ & $\begin{array}{r}-4.85 \pm \\
0.57 \mathrm{a}\end{array}$ & $\begin{array}{r}-4.33 \pm \\
0.50 \mathrm{a}\end{array}$ & $-4.33 \pm 0.50^{\mathrm{a}}$ & - \\
\hline $\mathrm{HC}$ & $0.68 \pm 0.29 \mathrm{a}$ & $\begin{array}{r}-4.85 \pm \\
0.81 \mathrm{a}\end{array}$ & $\begin{array}{r}-2.28 \pm \\
0.47 \mathrm{a}\end{array}$ & $2.28+0.47^{\mathrm{a}}$ & - \\
\hline HGT & $\begin{array}{r}-4.50 \pm \\
0.71 \mathrm{a}\end{array}$ & $\begin{array}{r}-3.60 \pm \\
0.50 \mathrm{a}\end{array}$ & $\begin{array}{r}-4.48 \pm \\
4.00 \mathrm{~b}\end{array}$ & $-4.48 \pm 4,00^{\mathrm{b}}$ & - \\
\hline HPR & $\begin{array}{r}-4.22 \pm \\
0.44 \mathrm{a}\end{array}$ & $\begin{array}{r}-3.96 \pm \\
0.20 \mathrm{a}\end{array}$ & $\begin{array}{r}-2.65 \pm \\
4.00 \mathrm{a}\end{array}$ & $-2.65 \pm .4 .00^{\mathrm{a}}$ & - \\
\hline HBPR & $\begin{array}{r}-3.00 \pm \\
1.05 \mathrm{a} \\
\end{array}$ & $\begin{array}{r}-3.09 \pm \\
0.78 \mathrm{a} \\
\end{array}$ & $\begin{array}{r}-150 \pm \\
0.70 \mathrm{a} \\
\end{array}$ & $-15.00 \pm 0.70^{\mathrm{a}}$ & - \\
\hline \multicolumn{6}{|c|}{ Weekly mean percent change in blood glucose level* } \\
\hline NHC & $\begin{array}{r}-0.41 \pm \\
0.70 \mathrm{a}\end{array}$ & $\begin{array}{r}-0.50 \pm \\
0.49 \mathrm{a}\end{array}$ & $\begin{array}{r}-1.55 \pm \\
1.51 \mathrm{~b}\end{array}$ & $-0.64 \pm 1.00 \mathrm{~b}$ & -4 \\
\hline $\mathrm{HC}$ & $\begin{array}{r}-78.0 \pm \\
5.76 \mathrm{a}\end{array}$ & $\begin{array}{r}-1.00 \pm \\
4.39 \mathrm{a}\end{array}$ & $\begin{array}{r}-1.04 \pm \\
3.64 \mathrm{a}\end{array}$ & $-0.58 \pm 4.19 \mathrm{a}$ & -3.54 \\
\hline HGT & $\begin{array}{r}16.91 \pm \\
4.33 \mathrm{a}\end{array}$ & $\begin{array}{r}16.70 \pm \\
2.20 \mathrm{a}\end{array}$ & $\begin{array}{r}15.14 \pm \\
1.66 \mathrm{c}\end{array}$ & $28.90 \pm 2.37 \mathrm{c}$ & 58.24 \\
\hline HPR & $13.1 \pm 1.99 \mathrm{a}$ & $\begin{array}{r}5.85 \pm \\
1.76 \mathrm{~b}\end{array}$ & $\begin{array}{r}11.68 \pm \\
1.66 \mathrm{c}\end{array}$ & $21.86 \pm 1.74 \mathrm{~d}$ & 43.56 \\
\hline HBPR & $\begin{array}{r}15.18 \pm \\
2.53 \mathrm{a}\end{array}$ & $\begin{array}{r}13.6 \pm \\
1.54 \mathrm{a}\end{array}$ & $\begin{array}{r}13.80 \pm \\
1.90 \mathrm{~b}\end{array}$ & $28.08 \pm 1.68 \mathrm{c}$ & 54.57 \\
\hline
\end{tabular}

${ }^{*}$ Means with positive $(+)$ sign means decrease.

C-commercial rodent feed;BPR-brown pigmented rice; NHC: nonhyperglycemic control, commercial rodent feed; HC:hyperglycemic, commercial rodent feed: HGT:hyperglycemic, commercial feed $+\mathrm{g}$

Glibenclamide: HPR: hyperglycemic, $50 \%$ commercial feed and 50\% well milled PR: HBPR: hyperglycemic, $25 \%$ commercial feed and $75 \%$ brown pigmented rice. Means within a group with same letter(s) are not significantly different at $\alpha=0.05$ using t-test. Blood glucose normal limit from acclimatization $=56.67 \mathrm{mg} / \mathrm{dL}$

STZ damages the pancreas of the liver and therefore there is no insulin secreted into the blood. Weight loss due to diabetes is associated with the tissue inability to take up blood glucose because there is no or less insulin. Consequently, the liver uses more the fatty acids and protein as energy source [14]. Thus, the observed reduced weight among HC rats.

Throughout the intervention period, blood glucose level of the NHC rats was maintained low and had almost similar value with the normal blood glucose observed in the acclimatization experiment. Within a group, blood glucose level in the HGT, HBPR and HPR rats deviated lower from $\mathrm{HC}$ rats but still did not reach the normal blood glucose value observed in the acclimatization period $(56.67 \mathrm{mg} / \mathrm{dL})$. The blood glucose level in HGT rats was the nearest to the blood glucose normal value followed by HBPR then HPR (Figure $3)$.

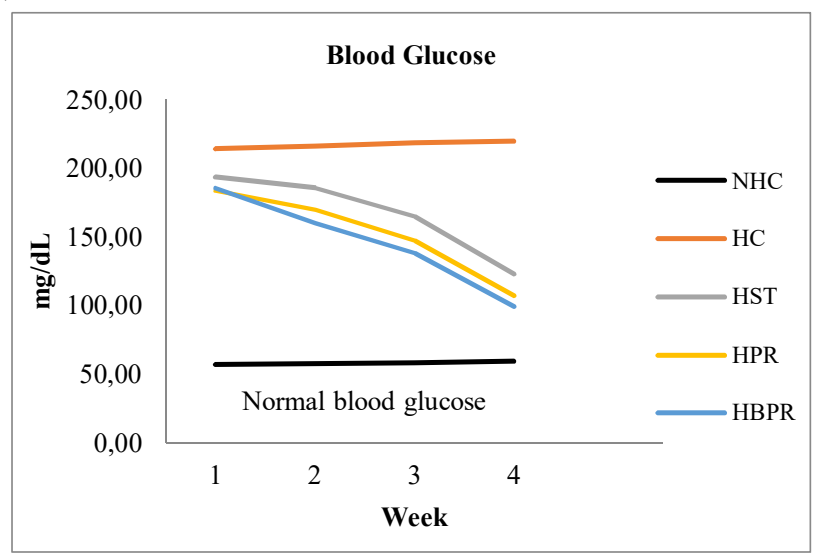

Fig. 3 Weekly mean blood glucose level in feed-induced hyperglycemic Sprague Dawley rats in thein vivo glucose lowering determination of $75 \%$ Segreng brown rice

The decrease in blood glucose level in rats fed with $75 \%$ brown pigmented rice (HBPR) was not significantly different from rats given Glibenclamide treatment (HGT), implying that the glucose-lowering ability of the brown pigmented is as par with Glibenclamide. Further, cumulative mean percent change (decrease) of blood glucose observed among HBPR treated rats was comparable with that of HGT-treated rats at 28.91 and $28.08 \%$, respectively. A cumulative increase in mean percent blood glucose was observed in NHC and $\mathrm{HC}$ rats (TABLE III). The glucose-lowering ability of Segreng could be attributed to its high amounts of dietary fiber $(55.9 \mathrm{~g}$ $/ 100 \mathrm{~g}$ ) and amylose content (17.22 g / $100 \mathrm{~g})$. The presence of dietary fiber can affect blood glucose levels where, in higher amounts, may contribute to a low glycemic index [5]. Dietary fiber can act as a barrier to digestion where it can slow food rate in the gastrointestinal tract and inhibit enzyme activity so the digestive process becomes slow, and the blood glucose response will be lower. Table II further shows that increasing the amount of BPR in the rice dose given to the rats also increases the reduction of blood glucose levels. Its amylose content may also bring about the blood glucose lowering ability of Segreng.

Starch granules consist of two fractions: amylose and amylopectin. Amylopectin is a simple, branched, and openended glucose polymer [15], whereas amylose is a straightchain glucose polymer. Higher amylose content causes digestion to be slower because amylose has an unbranched structure that has stronger hydrogen bonds than amylopectin, making it difficult to be hydrolyzed by digestive enzymes [16]. The blood-glucose-lowering effect was observed in Type 2 
diabetic patients when fed with high amylose white corn variety.

The intervention drug given to HGT group was glibenclamide. Glibenclamide is an oral antidiabetic drug similar to derivative sulfonylurea, which stimulates pancreatic $\beta$ cells to produce insulin, thereby reducing blood glucose levels. Therefore, it is only beneficial in adult diabetics whose pancreas is still capable of producing insulin. On oral administration, it is absorbed partially rapidly and spreads throughout the extracellular fluid, most of which are bound by plasma proteins. Administration of a single dose of glibenclamide can lower blood glucose levels in 3 hours, and this level will last for 15 hours. In the study, glibenclamide decreased blood glucose level until the end of the 4-week intervention period at $58.24 \%$, while $75 \%$ brown pigmented rice lowered blood glucose level to $54.57 \%$ (Table III).

The mechanism of BPR to reduce glucose levels is not yet known but is suspected to be related to the type and fiber content. Segreng has an intermediate GI and contains 5.59\% fiber content. Proposed mechanisms to elucidate the decrease in blood glucose by dietary fiber were as follows: 1) by delaying glucose uptake associated with elongation of gastric emptying time, carbohydrate intestine or digestive enzymes, and glucose transport impairment through a water layer formed by fibers; 2) insulin sensitivity and secretion, in which high dietary fiber can increase glucose methylation without increasing enzyme secretion and also increase insulin tissue sensitivity especially because its VFA (volatile fatty acid) product and; 3) fiber in foods increases the insulin receptors[17].

The bivariate correlation between micronutrient content in feed with blood glucose level at an effective dose $(25 \%$ commercial feed and $75 \%$ cooked brown pigmented rice) was also determined. Moreover, based on the results, calorie, carbohydrate, and fat are correlated significantly with blood glucose levels ( $p$-value $<0.05$ ), whereas protein did not correlate significantly with blood glucose levels. Therefore, calorie, carbohydrate, and fat intakes also affect blood glucose levels.

This study showed that the amount of the cooked Segreng brown pigmented rice variety to be consumed by humans to observe the same effects on glucose level is 301.86/day. The amount is equivalent to a household cup of $195 \mathrm{~g} / \mathrm{cup}, 1.62$ cups of cooked brown rice. Similarly, the estimated glycemic response of pigmented "red" rice was classified as moderate with a 68 relative to pure glucose of 100 was observed in the study using predicted and adjusted formulae in estimating glycemic index of different rice-based mixed meals [18]. The previous report has noted that replacing an estimate of 50 grams/day cooked white rice intake with the same amount of brown rice was associated with a $16 \%$ reduction of risk to type 2 diabetes [19]. Moreover, a 19.8\% decreased in glycemic response was observed in 5-day average white rice replacement with brown rice among overweight Asian Indians [20]. These findings further support the diet recommendation regarding the intake of more whole grains such as brown rice in regulating or controlling the blood glucose levels in hyperglycemic or diabetic individuals.

\section{CONCLUSION}

Results revealed that increasing the amounts of brown pigmented rice in the feed of the rats resulted in the lowering of the blood glucose levels. The Segreng variety exhibited relatively high amounts of dietary fiber at $5.59 \%$, moderate amylose content of $17.22 \%$, and also moderate glycemic index value of 55 . The inclusion of $75 \%$ cooked brown pigmented rice in the feed of rats for four weeks resulted in the reduction of blood glucose levels by $54.57 \%$, but the amounts were insufficient to bring the rats' blood glucose levels to normal values. The reduction of blood glucose levels in hyperglycemic rats fed with $75 \%$ brown pigmented rice was comparable with those of the rats given Glibenclamide drug $(58.24 \%)$ at $10 \mathrm{mg} / \mathrm{kg}$ body weight. Bivariate correlation analysis indicated a higher significant positive correlation of carbohydrate intake with blood glucose than fat, implying that carbohydrate intake (higher amylose and dietary fiber) is a good predictor of blood glucose level. Moreover, it is noted that consuming approximately 1.62 cups per day of $75 \%$ brown pigmented rice can reduce blood glucose. Further study is recommended using human subjects to conclusively claim the effect of consumption of brown pigmented rice to lower blood glucose, and it may also be replicated using other grains like corn, adlai, sorghum, and root crops.

\section{REFERENCES}

[1] P. D. med D. Müller-Wieland et al., "Definition, Classification and Diagnosis of Diabetes Mellitus," Diabetologe, vol. 15, no. 2, pp. 128 134, 2019, doi: 10.1007/s11428-019-0460-1.

[2] T. D. Mellitus, V. Argiana, P. T. Kanellos, I. Eleftheriadou, and G. Tsitsinakis, "nutrients Low-Glycemic-Index / Load Desserts Decrease Glycemic and Insulinemic Response in Patients with," pp. 1-9, 2020.

[3] Y. Granfeldt, L. Helena, A. Drews, R. Newman, and I. Björck, "Glucose of food and insulin responses to barley structure and amylose- . amylopectin products :," Am. J. Clin. Nutr., vol. 59, no. April, pp. 1075-1082, 1994.

[4] A. P. P. Tuaño, E. C. G. Barcellano, and M. S. Rodriguez, "Resistant Starch Levels and In Vitro Starch Digestibility of Selected Cooked Philippine Brown and Milled Rices Varying in Apparent Amylose Content and Glycemic Index," Food Chem. Mol. Sci., p. 100010, 2021, doi: 10.1016/j.fochms.2021.100010.

[5] N. Pellegrini, E. Vittadini, and V. Fogliano, "Designing food structure to slow down digestion in starch-rich products," Curr. Opin. Food Sci., vol. 32, pp. 50-57, 2020, doi: 10.1016/j.cofs.2020.01.010.

[6] W. A. Yulianto, "Influence of pandan leaf extract and fortificants addition and cooling duration to cooking quality, preference level, and glycemic index of brown parboiled rice fortified with chromium and magnesium," IOP Conf. Ser. Earth Environ. Sci., vol. 443, no. 1, 2020, doi: 10.1088/1755-1315/443/1/012099.

[7] A. Kumar et al., "Resistant starch could be decisive in determining the glycemic index of rice cultivars," J. Cereal Sci., vol. 79, pp. 348-353, 2018, doi: 10.1016/j.jcs.2017.11.013.

[8] A. C. Haldipur and N. Srividya, "In vitro glycemic response of indigenous pigmented rice cultivars from South India and influence of different carbohydrate components," Curr. Res. Nutr. Food Sci., vol. 8, no. 3, pp. 815-828, 2020, doi: 10.12944/CRNFSJ.8.3.13.

[9] J. B. Buse et al., "2019 update to: Management of hyperglycemia in type 2 diabetes, 2018. A consensus report by the American Diabetes Association (ADA) and the European Association for the Study of Diabetes (EASD)," Diabetes Care, vol. 43, no. 2, pp. 487-493, 2020, doi: 10.2337/dci19-0066.

[10] Z. K. Zhou, F. Wang, X. C. Ren, Y. Wang, and C. Blanchard, "Resistant starch manipulated hyperglycemia/hyperlipidemia and related genes expression in diabetic rats," Int. J. Biol. Macromol., vol. 75, pp. 316-321, 2015, doi: 10.1016/j.ijbiomac.2015.01.052.

[11] P. Wongsa, "Phenolic Compounds and Health Benefits of Pigmented Rice," in Recent Advances in Rice Research, https://www.intechopen.com/books/9669, 2020. 
[12] V. Krishnan, S. Raja and A. Singh. "Nutrient dense Pigmented Rice: A diet for Healthier People.," 2020.

[13] P. Cunniff and A. of O. A. Chemists., Official methods of analysis of AOAC international. Washington, DC: Association of Official Analytical Chemists, 1995

[14] Y. Mukhtar, A. M. Galalain, and U. M. Yunusa, "A Modern Overview on Diabetes Mellitus: A Chronic Endocrine Disorder,” Eur. J. Biol. vol. 4, no. 1, pp. 1-14, 2019.

[15] A. E. El-Hadary and M. F. Ramadan, "Phenolic profiles, antihyperglycemic, antihyperlipidemic, and antioxidant properties of pomegranate (Punica granatum) peel extract," J. Food Biochem., vol. 43, no. 4, pp. 1-9, 2019, doi: 10.1111/jfbc.12803.

[16] D. P. Belobrajdic et al., "High-amylose wheat lowers the postprandial glycemic response to bread in healthy adults: A randomized controlled crossover trial," J. Nutr., vol. 149, no. 8, pp. 1335-1345, 2019, doi: $10.1093 / \mathrm{jn} / \mathrm{nxz} 067$.

[17] N. Maria, "Nutritional, functional properties, glycemic index and glycemic load of," vol. 3, no. October, pp. 537-545, 2019.

[18] N. M. H. Osman, B. N. Mohd-Yusof, and A. Ismail, "Estimating Glycemic Index of Rice-Based Mixed Meals by Using Predicted and Adjusted Formulae," Rice Sci., vol. 24, no. 5, pp. 274-282, 2017, doi: 10.1016/j.rsci.2017.06.001.

[19] D. D. Handoko and S. D. Indrasari, "The Glycemic Index Value of Hipa 7 and the Determination Method," Kaunia Integr. Interconnect. Islam Sci., vol. 16, no. 1, p. 19, 2020, doi: 10.14421/kaunia.2148.

[20] B. Bhavadharini et al., "White rice intake and incident diabetes: A study of 132,373 participants in 21 countries," Diabetes Care, vol. 43, no. 11, pp. 2643-2650, 2020, doi: 10.2337/dc19-2335. 